\title{
Imagem cinematográfica e pensamento: a imagem-percepção na confluência de teorias de Deleuze e Peirce ${ }^{1}$
}

\author{
Maria Ogécia Drigo
}

\section{Resumo}

Este artigo apresenta resultados de pesquisa que envolve relações entre o pensamento e as imagens cinematográficas desenvolvidas por Gilles Deleuze, na obra Imagem-movimento Cinema 1, na confluência com teorias de Charles Sanders Peirce, especialmente a taxionomia dos signos e as categorias fenomenológicas. A fim de alcançar o objetivo de explicitar aproximações entre imagem-percepção, componente da imagem-movimento, conceito proposto por Deleuze nesta obra, à teoria da percepção e às categorias fenomenológicas, na perspectiva peirciana, bem como rever a classificação dada por Deleuze à imagem-percepção, seguindo a classificação de Peirce, apresentamos reflexões sobre 0 conceito de imagem-movimento, sobre a teoria da percepção e da fenomenologia da arquitetura filosófica empreendida por Peirce e, por fim, exploramos a classificação da imagem-percepção elaborada por Deleuze. A importância deste artigo está em colocar em evidência o potencial do entrelaçamento de ideias de Deleuze e de Peirce para a análise de imagens em movimento.

\section{Palavras-Chave}

Deleuze/Peirce. Imagem cinematográfica. Imagem-percepção.

Maria Ogécia Drigo I maria.drigo@yahoo.com.br Doutora em Comunicação e Semiótica pela Pontifícia Universidade Católica de São Paulo - PUCSP, Brasil. Pós-Doutora por meio da Escola de Comunicação e Artes da Universidade de São Paulo - USP, Brasil. Professora do Programa de Mestrado em Comunicação e Cultura da Universidade de Sorocaba - Uniso, Brasil. Coordenadora do GPIM Grupo de Pesquisa em Imagens Midiáticas.

\section{Introdução}

Este artigo apresenta resultados de pesquisa ${ }^{2} \mathrm{em}$ desenvolvimento, que tem como tema relações entre pensamento e imagens cinematográficas, a partir das teorias desenvolvidas por Gilles Deleuze, nas obras A imagem-movimento - Cinema 1 e $A$ imagem-tempo - Cinema 2, na confluência com ideias de Charles Sanders Peirce, especialmente a taxionomia dos signos e as categorias fenomenológicas. As obras de Deleuze mencionadas compõem o corpus desta pesquisa, cujo propósito primeiro é a compreensão de como o filósofo vincula as categorias fenomenológicas: primeiridade, segundidade e terceiridade e parte da taxionomia dos signos da arquitetura filosófica peirciana aos conceitos de imagem-movimento e imagem-tempo. A partir disso, propõe-se inventariar as contribuições destas teorias deleuzianas para a compreensão da relação entre pensamento e imagem, bem como explicitar estratégias metodológicas para análise de imagens em movimento.

Considerando-se as produções que, de algum modo, se reportam às obras de Deleuze 
mencionadas, na área da Comunicação, no

Brasil, constatamos que os conceitos de imagemmovimento e imagem-tempo ainda não foram explorados, notadamente no que diz respeito ao modo como adentra 0 fluxo das teorias peircianas. Em artigo de Silva e Araújo (2011), o estatuto semiótico da imagem-movimento e da imagemtempo é dado à luz da definição de signo, na perspectiva peirciana, sem adentrar as categorias fenomenológicas e a classificação dos signos.

\section{0 livro Cinema/Deleuze, organizado por}

André Parente e publicado em 2013, apresenta uma crítica do sistema-cinema criado por Deleuze nas suas duas obras citadas, bem como amplia a taxionomia nelas apresentada, considerando-se pesquisadores não contemplados pelo filósofo Deleuze. 0 organizador da obra enfatiza que a exploração do potencial dos conceitos imagem-movimento e imagem-tempo está longe de se esgotar.

Há também a obra de Mostafa e Cruz (2011)

Deleuze vai ao cinema, na qual encontramos reflexões sobre aspectos teóricos da filosofia de Deleuze na confluência com teorias de Henri Bergson, Charles Sanders Peirce, Nietzsche e contemporâneos de Deleuze, como Roland Barthes e Michel Foucault, bem como experimentações teóricas elaboradas a partir da imagem-tempo.
Sendo assim, os vínculos da taxionomia dos signos e da fenomenologia, que constam na arquitetura filosófica de Peirce, com os conceitos de Deleuze podem ainda ser explorados, assim como seria interessante pesquisar em que medida o pensamento deleuziano, desenvolvido nessas obras, pode contribuir para a elaboração de estratégias metodológicas para análise de imagens em movimento.

No que se refere às ideias peircianas, Deleuze explica que ele se refere a Peirce "porque ele (Peirce) estabeleceu uma classificação geral das imagens e dos signos, sem dúvida a mais completa e variada de todas. É como uma classificação de Lineu em história natural ou, mais ainda, como uma tabela de Mendeleiev em química". (DELEUZE, 2009, p. 11) Acrescenta ainda que 0 cinema requer "novos pontos de vista sobre este problema". (DELEUZE, 2009, p. 11)

Neste contexto, a exploração dos "novos pontos de vista" mencionados por Deleuze, notadamente os relacionados à classificação das imagens e dos signos no cinema, é pertinente. Assim sendo, vale analisar minuciosamente os conceitos de imagemmovimento e imagem-tempo, bem como explicitar e analisar as denominações dadas por Deleuze aos três componentes da imagem-movimento: imagempercepção, imagem-ação e imagem-afecção. Ele and Peirce's ideas, foi apresentada no 14th Annual International Conference on Communication and Mass Media, realizado em Atenas, Grécia, de 9 a12 de maio de 2016. 
comenta também que grandes autores do cinema, arquitetos, músicos e pintores pensam com imagens-movimento e imagens-tempo. Daí vem a questão: Peirce não teria pensado também com imagens-movimento e imagens-tempo?

0s possíveis resultados relacionados à compreensão do pensamento, enquanto ação de signos, assim como a possibilidade de que destas reflexões possam vir estratégias metodológicas para análise de imagem em movimento são avanços teóricos e metodológicos que vêm com esta pesquisa. Com a proliferação de imagens representações visuais - nas mais diversas mídias, o que contribui para que, em certa medida, 0 nosso cotidiano seja por elas invadida, justificaria a importância da pesquisa, uma vez que tais imagens passam cada vez mais a compor 0 corpus de pesquisas nas mais diversas áreas. Logo, cabe ir além da análise dos sentidos produzidos pela linguagem verbal, ou pelas imagens impressas, paralisadas, tentando abarcar os sentidos construídos pelas imagens em movimento. A compreensão da relação entre imagem e pensamento, ao mostrar como o pensamento caminha com imagens, com signos, pode auxiliar a desenhar o mapa de relações possíveis na interação entre os usuários/intérpretes e os processos e produtos midiáticos, ou seja, exibem as possibilidades de configuração da comunicação enquanto processo de interação.

Com esta pesquisa, vem também a possibilidade de colocarmos as teorias de Deleuze e de Peirce em um mesmo fluxo, na mesma corrente, ou ainda, em contracorrente, para deste movimento extrair outra "engrenagem", pois, conforme Deleuze (1990), há duas formas de ler um livro: a primeira é a que suscita interpretações e faz com que infinitos livros sejam escritos, ou seja, com esta forma de ler escreve-se o livro do livro e assim sucessivamente; a segunda opõe-se à primeira, já que um livro "é uma pequena engrenagem numa maquinaria exterior muito complexa. Escrever é um fluxo entre outros e que não tem qualquer privilégio relativamente aos outros, e que entra em relações de corrente, de contracorrente, de turbilhão com outros fluxos". (DELEUZE, 1990, p. 18)

Este artigo, portanto, enquanto relata resultados da pesquisa mencionada, atém-se às aproximações entre a teoria da percepção e as categorias fenomenológicas, na perspectiva peirciana, à imagem-percepção, componente da imagem-movimento, conceito proposto por Deleuze. Para tanto, apresentamos reflexões sobre 0 conceito de imagem-movimento, aspectos da teoria da percepção e da fenomenologia da arquitetura filosófica empreendida por Peirce e, por fim, analisamos os conceitos e adentramos a classificação da imagem-percepção, enquanto signo, dada por Deleuze.

\section{Sobre imagem-movimento}

Nesta parte, anunciamos as divisões da imagemmovimento. Neste sentido, convém iniciar com a concepção de percepção apresentada em $A$ 
imagem-movimento Cinema 1, de Deleuze, a partir de teorias de Bergson, notadamente as que constam na obra Matéria e Memória. Com as teorias então apresentadas por Bergson, conforme Deleuze (2009, p. 11), não era mais possível opor 0 "movimento como realidade física no mundo exterior à imagem como realidade psíquica na consciência", ou seja, tais teorias demonstraram a identidade entre imagem e movimento e, mais especificamente, entre imagem-movimento e matéria.

0 movimento, segundo as teorias de Bergson, de um lado "é aquilo que se passa entre objetos ou partes, por outro é aquilo que exprime a duração ou o todo". (DELEUZE, 2009, p. 27) Os objetos ou partes de um conjunto são denominados cortes móveis, e 0 "movimento estabelece-se entre esses cortes e relaciona os objetos ou partes com a duração de um tudo que muda, exprime portanto a mudança do todo relativamente aos objetos e ele próprio é um corte móvel da duração". (DELEUZE, 2009, p. 27) Não há somente imagens instantâneas, ou cortes imóveis do movimento, mas imagens-movimento, as quais são cortes móveis da duração.

0 plano é a imagem-movimento, ou seja, é um corte móvel de uma duração, pois refere 0 movimento a um todo que muda. É próprio da imagem-movimento cinematográfica "extrair de veículos ou dos corpos móveis o movimento que é sua substância comum, ou extrair dos movimentos a mobilidade que é sua essência". (DELEUZE, 2009, p. 44)
E qual é o papel da percepção na constituição da imagem-movimento? Há "três tipos de imagens que a imagem-movimento se divide: (...) imagenspercepção; imagens-ação e imagens-afecção". (DELEUZE, 2009, p. 107) Esta divisão, conforme Deleuze (2009, p. 98), vem da concepção de que a percepção e a linguagem distinguem corpos, qualidades e ações, sendo que o corpo "substitui 0 movimento pela ideia de um sujeito que o executaria ou de um objeto que o sofreria, de um veículo que 0 transportaria"; a qualidade, por sua vez, "substitui o movimento pela ideia de um estado que persiste enquanto não lhe suceder outro", e, por fim, as ações substituem "o movimento pela ideia de um lugar provisório para onde ele se dirige ou de um resultado que ele obtém". De acordo com Deleuze (2009, p. 98), as imagens, na sua materialidade, não são coisas concebidas como corpos, mas como qualidades, ou ações.

0 duplo regime de referência de imagens dado por Bergson torna clara a diferença entre a coisa e a percepção da coisa. Segundo Deleuze (2009, p. 103), "a coisa e a percepção da coisa são uma só e mesma coisa, uma só e mesma imagem, mas referida a um ou a outro dos dois sistemas de referência". "A coisa é a imagem tal como ela é em si, tal como se refere a todas as outras imagens das quais sofre integralmente a ação e sobre as quais reage imediatamente." (DELEUZE, 2009, p. 103) Assim, a coisa constitui uma imagem referida ao primeiro sistema, ou seja, segundo Deleuze (2009, p. 102), "um sistema em que cada imagem varia 
para si mesma e em que todas as imagens agem e reagem em função umas das outras, em todas as suas faces e em todas as suas partes". A percepção da coisa, por sua vez, conforme Deleuze (2009, p. 103-4), "é a mesma imagem referida a uma outra imagem especial que a enquadra e que só retém dela uma ação parcial e só reage a ela mediatamente", ou seja, esta imagem refere-se ao sistema "em que todas variam principalmente para uma só, que recebe a ação de outras imagens numa das suas faces e lhe reage noutra face". (DELEUZE, 2009, p. 102)

Sobre a natureza mediada da percepção da coisa, Deleuze (2009, p. 104) explica:

Percepcionamos a coisa menos aquilo que não nos interessa em função das nossas necessidades. Por necessidade ou interesse deve entender-se as linhas e pontos que retemos da coisa em função da nossa face receptora e as ações que selecionamos em função das ações retardadas de que somos capazes. 0 que é uma maneira de definir o primeiro momento material da subjetividade: ela é subtrativa, ela subtrai da coisa o que não Ihe interessa. Mas, inversamente, é preciso nesse caso que a própria coisa se apresente em si como uma percepção, e como uma percepção completa, imediata, difusa. A coisa é imagem e, a esse título, percepciona-se a si mesma e percepciona todas as outras na medida em que thes sofre a ação e reage a esta em todas as suas partes.

Mas a percepção não se constitui somente com a subtração. Há também a ação, uma resposta imprevista, que só é possível porque, ao percepcionar a coisa, uma face recebeu uma excitação privilegiada e as demais foram eliminadas, o que "equivale a dizer que toda percepção é antes de mais sensório-motora". (DELEUZE, 2009, p.105)

A imagem-percepção cede lugar à imagem-ação e, de acordo com Deleuze (2009), passamos de uma a outra, insensivelmente. A imagem-ação, conforme Deleuze (2009, p. 106), é o "segundo aspecto material da subjetividade". E, assim como a percepção refere o movimento a "corpos" (substantivos), quer dizer, a objetos rígidos que vão servir de móveis ou de movidos, a ação refere 0 movimento a "atos" (verbos) que serão o desenho de um termo ou de um resultado supostos.

Até então temos que a imagem-movimento constitui-se com a imagem-percepção, a qual corresponde ao primeiro aspecto material da subjetividade, a subtração, e com a imagem-ação, o segundo aspecto material da subjetividade, que corresponde à ação virtual das coisas sobre nós e nossa ação possível sobre as coisas. No entanto, há ainda o terceiro aspecto material da subjetividade, a imagem-afecção.

A afeção é aquilo que ocupa o intervalo, aquilo que o ocupa sem 0 encher ou o tapar. Ele surge no centro da indeterminação, isto é, no sujeito, entre uma percepção sob certos aspectos perturbante e uma ação hesitante. Ela é uma coincidência do sujeito e do objeto, ou a maneira como o sujeito se percepciona a si mesmo, ou antes, faz a experiência de si ou se sente "de dentro" (terceiro aspecto material da subjetividade). Ela refere o movimento a uma "qualidade" como estado vivido (adjetivo). (DELEUZE, 2009, p. 106). 
A percepção não só retém ou reflete 0 que nos interessa, como também não deixa passar o que, em um primeiro momento, nos parecia indiferente. A importância disso é enfatizada por Deleuze (2009, p. 106-107).

Há forçosamente uma parte de movimentos exteriores que "absorvemos", que refratamos, e que não se transformam nem em objetos de percepção nem em atos do sujeito; em vez disso eles vão marcar a coincidência do sujeito e do objeto numa qualidade pura. É esse 0 último avatar da imagem-movimento: a imagem-afeção. Seria um erro considerá-lo como uma falha do sistema percepção-ação. Pelo contrário, é um terceiro dado absolutamente necessário.

Após a exposição dos três tipos de imagemmovimento, Deleuze procura os signos que lhes correspondem na semiótica ou lógica peirciana. Ele também associa cada um dos três tipos de imagem-movimento às categorias fenomenológicas instituídas por Peirce. No âmbito deste artigo, vamos analisar a imagempercepção. Assim, faz-se pertinente tratar da percepção, à luz da semiótica peirciana, e, em linhas gerais, das categorias da fenomenologia: primeiridade, segundidade e terceiridade, bem como dos tipos de consciência para assim esclarecer a passagem da percepção à ação.

\section{Aspectos da percepção e da fenomenologia, na perspectiva peirciana}

\author{
Conforme tratamos em Drigo (2007) e em Drigo
} e Souza (2013), a fenomenologia é uma quaseciência que "apura e estuda os tipos de elementos presentes no fenômeno" (CP 1.186) e, com as Ciências Normativas e a Metafísica, integra as três divisões da Filosofia ${ }^{3}$.

A fenomenologia não é uma ciência da realidade, pois ela busca as especificidades do fenômeno que permanecem restritos à sua aparência e, para permanecer nesse nível, Peirce enfatiza a necessidade de se construir olhos mentais, ou seja, é preciso "olhar bem para o fenômeno e dizer quais são as características que nele nunca estão ausentes, seja este fenômeno algo que a experiência externa força sobre nossa atenção, ou seja, o mais selvagem dos sonhos ou a mais abstrata e geral das conclusões da ciência". (CP 5.41)

As categorias fenomenológicas instituídas por Peirce fundamentam-se na lógica dos relativos e emergiram também de acordo com os três modos pelos quais se constitui a experiência,

Em Drigo (2007, pp. 66-70), tratamos da classificação das ciências, explicando que toda ciência é Ciência da Descoberta; ou Ciência da Revisão; ou Ciência Prática (CP 1.181). A primeira divide-se em Matemática, Filosofia e Ideoscopia (CP 1.183). A Filosofia, por sua vez, divide-se em Fenomenologia, Ciências Normativas e Metafísica, sendo que as Ciências Normativas dividem-se em Estética, Ética e Lógica ou Semiótica (CP 1. 191). Sobre a semiótica ou lógica, nas palavras de Peirce: "All thought being performed by means of signs, logic may be regarded as the science of the general laws of signs. It has three branches: 1, Speculative Grammar, or the general theory of the nature and meanings of signs, whether they be icons, indices, or symbols; 2, Critic, which classifies arguments and determines the validity and degree of force of each kind; 3, Methodeutic, which studies the methods that ought to be pursued in the investigation, in the exposition, and in the application of truth. Each division depends on that which precedes it." (CP 1.191). 
a saber: por meio da qualidade (relação monádica), da alteridade (relação diádica) e da mediação (relação triádica), modos de aparecer que constituem as categorias denominadas primeiridade, segundidade e terceiridade, respectivamente (CP 1.346-347).

Peirce (CP 1.293) explica que um estudo completo da lógica dos relativos mostra que os termos lógicos, os quais explicam as relações entre os objetos, são os seguintes: mônada, díade ou políada, sendo que esta última não introduz qualquer elemento diferente dos encontrados na tríade.

Como primeiridade, categoria que corresponde à relação monádica, tem-se um primeiro modo do aparecer, dado pelas qualidades do fenômeno. É algo que não reage, que se apresenta como um objeto que não resiste, pura possibilidade. As qualidades da cor, do som, do odor, do prazer estão presentes em fenômenos completos em si mesmos e que se constituem em livres possibilidades de experiência. A vermelhidão, por exemplo, existe sem que alguém possa imaginá-la ou percebê-la em uma realização, ou seja, ela existe independentemente de um confronto ou de uma ideia que a mente humana possa construir envolvendo-a.

Outro modo do fenômeno aparecer é o da alteridade, da resistência, a qual corresponde à relação diádica. É algo que se opõe à vontade, à expectativa. Os fatos brutos sempre nos afrontam e burlam as nossas expectativas. "Esperávamos uma coisa ou passivamente tomávamo-la por admissível e tínhamos sua imagem em nossas mentes, mas a experiência força esta ideia ao chão e nos compele a pensar muito diferentemente." (CP 1.324) "É ação mútua entre duas coisas sem considerar qualquer tipo de terceiro ou meio e, em particular, sem considerar qualquer lei de ação." (CP 1.322) A segundidade se firma por esse modo de aparecer objetual.

A terceiridade não se reduz às qualidades, atreladas ao modo de se firmar da primeiridade ou aos embates da segundidade. É a categoria das relações triádicas. "É a ideia daquilo que é tal qual é por ser um Terceiro ou Meio entre um Segundo e seu Primeiro." (CP 5.66) Terceiridade é, portanto, mediaçã $0^{4}$.

0 processo de mediação está presente na definição de signo de Peirce, que é triádica. Para Peirce (CP 6.347), "um signo pretende representar, pelo menos em parte, um objeto que é, portanto, num certo sentido a causa fundante deste signo. Mas dizer que ele representa seu objeto implica em que ele afete uma mente, de tal modo que nela determine algo devido ao objeto. Esta determinação da qual a causa imediata ou determinante é o signo, e cuja causa mediada é o objeto, pode ser chamada interpretante". Deleuze explica que não conhece a relação que Peirce propõe entre o signo e a imagem, no entanto, "é certo que a imagem dá lugar a signos. Pela nossa parte, um signo parece-nos ser uma imagem particular que representa um tipo de imagem, ou do ponto de vista da sua composição, ou do ponto de vista da sua gênese ou da sua formação (ou até da sua extinção). Teremos de confrontar a classificação das imagens e dos signos que propomos com a grande classificação de Peirce: por que é que elas não coincidem, nem mesmo ao nível das imagens distinguidas?" (DELEUZE, 2009, p. 112). Convém explicar, para o contexto deste artigo, uma vez que as ideias de Deleuze, postas neste trecho, permitem inúmeros desdobramentos, que imagem para Peirce é uma modalidade de representação, a qual assim se denomina devido a uma relação de semelhança com o objeto. No processo de percepção, em nenhum momento, Peirce se vale do termo imagem, justamente pelo fato de que na percepção não há mediação. 
Enquanto a fenomenologia nos mostra 0 mundo como aparência, a teoria da percepção explica como recolhemos as coisas do mundo. A percepção, à luz das teorias peircianas, envolve, principalmente, os conceitos de percepto, percipuum e juízo perceptivo.

Segundo Peirce (CP 7.621), o percepto não dá explicações, não pede desculpas e nem se defende por estar diante do percepiente. É uma coisa forte que, silenciosamente, se força sobre ele. 0 percepto é "muito insistente, devido a todo seu silêncio". (CP 7.620) A sua presença é perturbadora e não há como afastá-lo, a não ser com algum esforço físico. 0 percepiente, conforme Peirce (CP 7.643), não sabe nada sobre o percepto, a não ser o que vem com o julgamento ou juízo perceptivo. Mas ele sente 0 golpe, a reação do percepto e vê o seu conteúdo em um objeto, na sua totalidade, enquanto o "percebido" vem com 0 juízo perceptivo.

0 juízo perceptivo acompanha o percepto, que "não é a única coisa que dizemos normalmente que 'percebemos'; e quando eu professo crer somente o que eu percebi, é claro que eu não quis dizer perceptos, desde que eles não são sujeitos de crença ou descrença. Eu quis dizer julgamentos perceptivos". (CP 7. 626) 0 julgamento perceptivo não pode ser considerado um produto da percepção, pois, na relação com o conhecimento e com a crença, ele é como o percepto, tanto que Peirce (CP 7.629) propõe o termo percipuum, para incluir tanto o percepto como o julgamento perceptivo. Assim, Peirce considera "0 percepto como ele é imediatamente interpretado no julgamento perceptivo, sob o nome de 'percipuum'”. (CP 7. 626) Ele é que se impõe para ser reconhecido, sem qualquer motivo.

0 percepto é composto, conforme Peirce (CP 7.625), por dois tipos de elementos: os da primeiridade e os da segundidade. Os da primeiridade são "as qualidades de sentimento ou sensação, cada uma das quais é algo positivo e sui generis, sendo tal como é independentemente de como ou do que qualquer outra coisa seja". Tais elementos do percepto são conectados a formas. A "vivacidade com que o percepto se destaca é um elemento de segundidade; porque 0 percepto é nítido em proporção à intensidade do seu efeito sobre o percepiente." (PEIRCE CP 7.625) São esses elementos de segundidade que garantem a singularidade peculiar do percepto.

Para Peirce (CP 5. 181), o juízo perceptivo é 0 ponto de partida de todo o pensamento crítico e controlado, ou seja, o significado de qualquer representação, de qualquer tipo de cognição, está nele assentado. Desse modo, 0 que adentra a consciência sintética provém de juízos perceptivos, os quais são, em um sentido amplo, inferências abdutivas, considerandose que a abdução deve ser entendida como a adoção provisória de uma hipótese explicativa. Mas o que diferencia o juízo perceptivo da inferência abdutiva? 
Ambos são igualmente falíveis, porque hipotéticos. No entanto, o julgamento de percepção tem algo de insistente, compulsivo, algo que obstrui nosso caminho e que somos obrigados a reconhecer, enquanto a inferência abdutiva é mais gentil. Ela nasce em momentos de soltura, de entretenimento quase lúdico do pensamento consigo mesmo, por isso mesmo, é destituída de certeza. 0 julgamento de percepção, ao contrário, embora falível, é indubitável. Nossa vida ficaria insana, esquizofrênica, não conseguiríamos sequer sobreviver, se estivéssemos a todo instante colocando nossos julgamentos de percepção em dúvida. Por isso mesmo, nossas abduções podem e devem ser submetidas à crítica, enquanto os julgamentos de percepção não. (SANTAELLA, 1998, p. 67).

De acordo com Peirce (CP 2.539 - 540), 0

objeto imediato ${ }^{5}$ de todo pensamento é, em última análise, o percepto. Ele explica ainda que os psicólogos em geral - isso se refere aos estudos realizados até os da época em que Peirce escreveu essas ideias, evidentemente entendiam que a percepção consistia em um desfilar de imagens diante da mente, como se estivéssemos andando por uma galeria de quadros. Mas isso não é assim, pois o juízo perceptivo, que compõe a percepção com 0 percepto e o percipuum, que tem a natureza de uma conclusão, com elementos gerais, constitui o ponto de partida ou primeira premissa de todo pensamento crítico ou autocontrolado.

Postos, então, alguns aspectos da percepção e da fenomenologia, que consideramos adequados para dar conta das reflexões que seguem, convém ressaltar que, com o que foi apresentado, estamos longe de esgotar todas as implicações possíveis dos conceitos envolvidos na percepção e na fenomenologia da arquitetura filosófica de Peirce, uma vez que com eles caminhamos da definição de signo ao pragmaticismo. Seguem, então, as reflexões envolvendo o conceito de imagempercepção que anunciamos para este artigo.

\section{Reflexões na confluência de ideias de Deleuze e de Peirce}

Deleuze distingue a coisa e a coisa percebida. A coisa, que "é a imagem tal como ela é em si", corresponderia ao percepto, no processo perceptivo visto à luz das ideias peircianas; a coisa percebida, ou imagem-percepção, corresponderia ao par percipuum/juízo perceptivo. Na perspectiva peirciana, 0 produto da percepção, na sequência da imagem-percepção, a imagem-ação, teria como ponto de partida o juízo perceptivo. Ao propor 0 terceiro componente da imagem-movimento, a imagem-afeção, Deleuze, em certa medida, mostra que aspectos qualitativos também compõem a imagem-movimento. A imagemafeção resgata aspectos não percepcionados, quando da subtração, ou na constituição da imagem-percepção. 
"Passamos insensivelmente da percepção para a ação", refere Deleuze, o que nos leva a inferir que a imagem-ação precisa ser vista como algo que se dá na seara da segundidade. Como a imagemafeção está "entre dois", conforme Deleuze, então, a imagem-movimento, que envolve a imagempercepção, a imagem-ação e a imagem-afeção, se dá na segundidade.

Vamos à classificação de Deleuze dada à imagempercepção e que segue a elaborada por Peirce. Referindo-se à imagem-percepção, Deleuze (2009, p. 122) explica que, valendo-se "de um termo de Peirce, poderíamos chamar-lhe dicissigno", ou como mencionamos sinsigno indicial dicente.

Segundo Peirce (CP 251):

Um signo dicente é um signo que, para seu interpretante, é um signo de existência real. Portanto, não pode ser um ícone o qual não dá base para interpretá-lo como sendo algo que se refere a uma existência real. Um dicissigno necessariamente envolve, como parte dele, um rema para descrever o fato que é interpretado como sendo por ela indicado. Mas este é um tipo especial de rema, e, embora seja essencial ao dicissigno, de modo algum o constitui.

Mas, após classificar a imagem-percepção como um dicissigno, onde prepondera 0 aspecto indicial, Deleuze vislumbra a possibilidade do rema preponderar, dando como exemplo as imagens cinematográficas da escola francesa, que construía "uma consciência em ato que amplificava o movimento e o levava até a matéria". (DELEUZE, 2009, p. 123) Deleuze explica este movimento. Nas suas palavras:
No fim de contas, aquilo que a escola francesa encontrava na água era a promessa ou a indicação de um outro estado de percepção: uma percepção mais do que humana, uma percepção que já não era talhada nos sólidos, que já não tinha 0 sólido por objeto, por condição, por meio. Uma percepção mais fina e mais vasta, uma percepção molecular, própria de um "cine-olho". E era de fato esse o resultado, quando se partia de uma definição real dos dois polos da percepção: a imagem-percepção não ia refletir-se numa consciência formal mas cindir-se em dois estados, um molecular e 0 outro molar, um líquido e o outro sólido, um arrastando e apagando 0 outro. 0 signo de percepção não seria portanto um dicissigno mas um rema. Ao passo que 0 dicissigno traçava um quadro que isolava e solidificava a imagem, o rema remetia a uma imagem que se tornava líquida e que passava através ou sob o quadro. A consciência-câmara tornava-se um rema, porque se atualizava numa percepção fluente e atingia assim uma determinação material, uma matéria-fluxo. (DELEUZE, 2009, p. 127-8).

A imagem-percepção poderia, então, ser também classificada como sinsigno indicial remático, lembrando que um rema "é um signo que, para seu interpretante, é um signo de possibilidade qualitativa, ou seja, é entendido como representando esta e aquela espécie de objeto possível. Todo rema propiciará, talvez, alguma informação, mas não é interpretado nesse sentido". (CP 250) Assim, à luz das ideias peircianas, a imagem-percepção pode ser classificada, seguindo também a dada por Deleuze, como sinsigno indical dicente ou sinsigno indical remático.

Retomando Peirce... Ao tratar das diferenças entre percepto e juízo perceptivo, ele explica que 
o percipiente, diante de uma cadeira amarela, emite 0 seguinte juízo perceptivo: "Aquela cadeira parece amarela". A cor amarela, no caso, é um predicado. "Este predicado não é a sensação envolvida no percepto, porque é geral. Ele nem sequer se refere particularmente a este percepto, mas a uma espécie de fotografia composta de todos os amarelos que foram vistos." (CP 7. 634) Esta qualidade de sentimento, vinculada à cor amarela, a qual poderíamos chamar de imagemafeção, também pode guiar a ação, contribuindo para que o primeiro nível de consciência se atualize. Assim sendo, os aspectos icônicos do percepto preponderam.

Peirce (CP 7. 635) explica que o juízo perceptivo traduzido por "'aquela cadeira é amarela' seria mais precisamente representado assim: 'é amarelo', como um dedo apontador tomando 0 lugar do objeto. No seu conjunto, está bastante claro que o julgamento perceptivo não é uma cópia, ícone ou diagrama do percepeto", mas um índice. Neste aspecto, predominam os aspectos indiciais do percepto.

De acordo com Peirce (CP 7.628), o juízo perceptivo não se assenta em uma premissa, uma vez que o percepto não é uma proposição e também, na sua aparência, não se assemelha ao percepto. Desse modo, o fundamento que 0 autoriza a representar o percepto - não logicamente, portanto - é uma conexão real, como um índice. Assim, no nível perceptivo, há uma relação entre iconicidade e indicialidade.

Daí as duas possibilidades de classificação já dadas. Consideramos, entretanto, que estas duas classificações referem-se às imagens-ação e não às imagens-percepção. Dessa forma, imagempercepção dá passagem à imagem-ação: sinsigno indicial remático ou sinsigno indicial dicente. A imagem-percepção se restringiria à imagem que se constitui com a tríade percepto/percipuum/ juízo perceptivo.

Quando Deleuze procura nomear a imagempercepção, seguindo a classificação empreendida por Peirce, bem como compreendê-la no âmbito da fenomenologia, percebe-se uma certa vagueza. Talvez, os níveis de consciência propostos por Peirce possam contribuir para acrescentar explicações para tal passagem. Vejamos os níveis de consciência propostos por Peirce que, como ele ressalta, se fazem no movimento dos signos/ interpretantes, ou na semiose. Há três níveis de consciência (Fig. 1). 
Figura 1: Diagrama para os níveis de consciência sintética

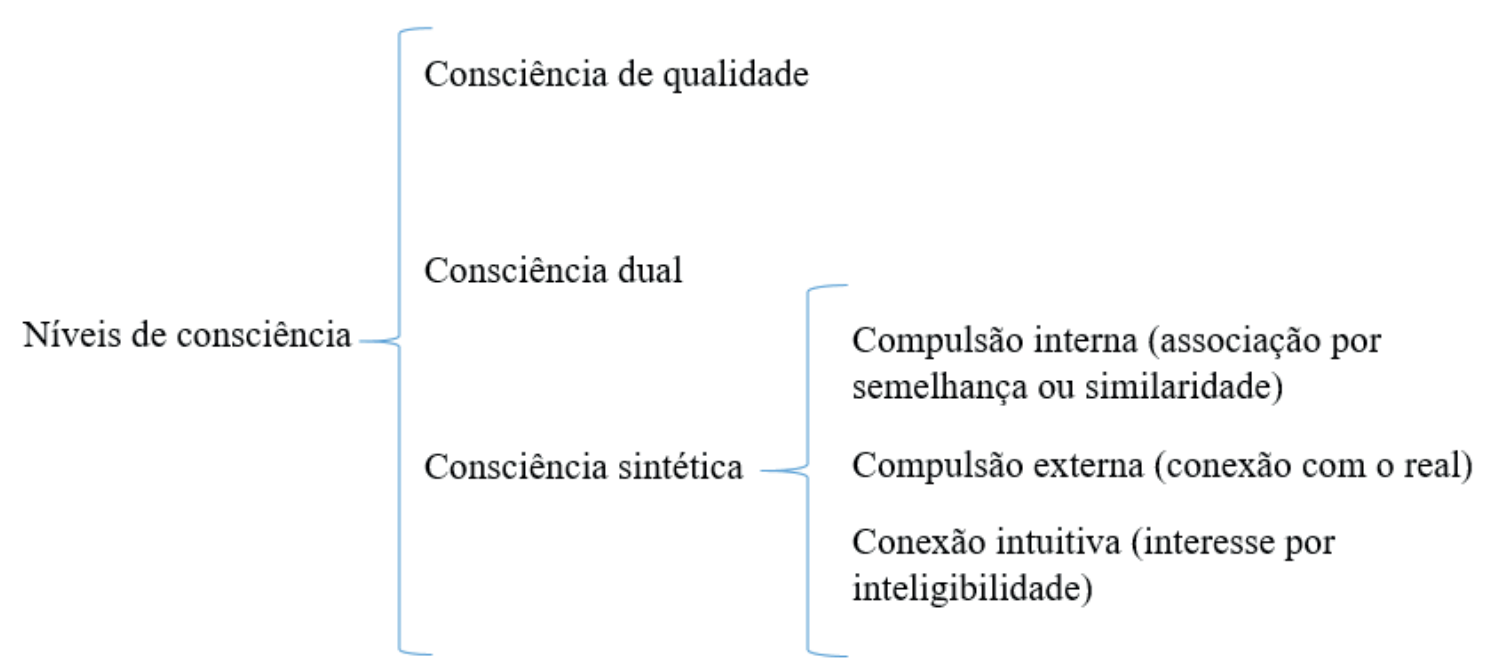

Fonte: Elaborado pela autora seguindo CP 1.377 e CP 1.378 .

São eles, em correspondência com as categorias fenomenológicas, conforme Peirce (CP 1.377): primeiro, "a consciência passiva, sem recognição ou análises; segundo, consciência de uma interrupção no campo da consciência, sentido de resistência, de um fato externo; terceiro, consciência sintética, ocorrendo no tempo, sentido de aprendizagem, pensamento". Peirce (CP 1.387) explica que a consciência sintética inclui: 0 sentido de similaridade; 0 de conexão real e 0 sentido de aprendizagem. Nas suas palavras:

A concepção de qualidade, a qual é absolutamente simples nela mesma e, contudo, observada nestas relações ela parece ser completa de variedade, surgiria em qualquer momento quando sentimento ou consciência singular se torna proeminente. A concepção de relação vem da consciência dual ou sentido de ação e reação. A concepção de mediação emerge da consciência plural ou sentido de aprendizagem. (PEIRCE, CP 1.378).
Peirce (CP 1.383) vale-se da ideia de compulsão para explicitar os três tipos de consciência sintética (Fig. 1) e menciona que o nível maior de síntese não se dá com atração de feeling ou representações deles, nem por força de necessidade, mas por interesse de inteligibilidade, que denomina de conexão intuitiva. Dessa maneira, a compulsão que acompanha a percepção a insere na seara da segundidade, e que envolve o percepto, o percipuum e o juízo perceptivo, conforme Peirce; ou a imagempercepção, em Deleuze, pode contribuir para que um dos níveis da consciência sintética possa ser alcançado. Mas, em sendo o juízo perceptivo - um quase-signo - ou um índice, na relação com o que representa fracamente, como isso seria possível?

Peirce (CP 1.311) esclarece que toda operação da mente, ainda que complexa, tem seufeeling 
absolutamente simples, a emoção da totalidade. É umfeeling secundário ou sensação provocada de dentro da mente. A ação do signo se dá em um continuum de sentimento. A relação indexicalidade/iconicidade posta pela imagempercepção torna-se imprescindível para que 0 terceiro nível da consciência sintética se firme, uma vez que esta pode construir um tecido qualitativo para permear futuras semioses.

Desse modo, imagem-percepção dá passagem à imagem-ação: sinsigno indicial remático ou sinsigno indicial dicente, e o nível de consciência desliza para o primeiro, consciência de qualidade, ou permanece no segundo, o da consciência dual. A imagem-percepção se restringiria à imagem que se constitui com a tríade percepto/percipuum/ juízo perceptivo. A classificação dada por Deleuze à imagem-percepção adequa-se, portanto, à imagem-ação, mas considera apenas duas possibilidades.

Contudo, se o nível de indicialidade envolvido na passagem imagem-percepção/imagem-ação for o degenerado, que ameniza 0 embate, a forte conexão com existentes e dá vazão ao poder de alusão, de sugestão, com potencial para atualizar o primeiro nível de consciência, a consciência de qualidade, então a semiose pode ser desencadeada. Isto porque, neste tecido qualitativo, assentado no juízo perceptivo, outros aspectos do percepto (agora compondo o objeto imediato do signo) podem ser retomados. Se a semelhança ou similaridade preponderar nesta retomada, ou seja, se com as qualidades intensificase 0 poder de sugestão para com 0 objeto percepcionado, então, a imagem-ação faz-se legissigno icônico remático, e os interpretantes serão os dinâmicos emocionais. Se a conexão com 0 existente predominar, ou seja, se marcas do objeto invadirem a imagem-ação, então esta se faz legissigno indicial remático ou dicente e os interpretantes serão os dinâmicos emocionais ou energéticos, respectivamente.

Se 0 interesse por inteligibilidade preponderar, então, os aspectos de lei, regras ou convenções impregnam o movimento do pensamento e as imagens se fazem legissignos simbólicos, que, na relação com 0 interpretante, podem ser remas, dicentes ou argumentos, cujos interpretantes podem ser denominados, respectivamente, emocionais, energéticos ou lógicos. São estes últimos que, ao prevalecerem, desencadeiam a reflexão ou colocam os signos em movimento, em ação... é a vez das imagens-tempo.

Os conceitos envolvidos nas reflexões apresentadas constam no Quadro 1. 
Quadro 1: Classificações para imagem-percepção, conforme Deleuze e Peirce

\begin{tabular}{|l|l|l|l|l|}
\hline Deleuze/Bergson & \multicolumn{1}{|c|}{ Deleuze } & \multicolumn{1}{|c|}{ Peirce } & Deleuze/Peirce & \multicolumn{1}{|c|}{ Nova classificação } \\
\hline $\begin{array}{l}\text { Coisa/ } \\
\text { Imagem- } \\
\text { percepção }\end{array}$ & $\begin{array}{l}\text { Percepto/Percipuum/ } \\
\text { Juízo perceptivo }\end{array}$ & Dicissigno & \\
\hline & $\begin{array}{l}\text { Imagem-ação } \\
\text { e Imagem/ } \\
\text { afeção }\end{array}$ & $\begin{array}{l}\text { Efeito a partir } \\
\text { do juízo perceptivo } \\
\text { enquanto índice }\end{array}$ & $\begin{array}{l}\text { Sinsigno indicial dicente } \\
\text { Sinsigno indicial remático } \\
\text { Legissigno indicial dicente } \\
\text { Legissigno indicial remático } \\
\text { Legissigno indicial dicente } \\
\text { Legissigno simbólico remático } \\
\text { Legissigno simbólico dicente } \\
\text { Legissigno simbólico argumentativo }\end{array}$ \\
\hline
\end{tabular}

Fonte: Elaborado pela autora a partir das reflexões que constam neste item do artigo

Esta classificação leva em conta somente as dez primeiras classes de signos dadas por Peirce (Fig. 2). Se percorrermos o diagrama (Fig. 2) sempre tomando duas setas em sequência, encontramos dez classes de signos. Por exemplo, um signo de lei - legissigno -, na relação com seu objeto, pode prevalecer como símbolo, enquanto seu efeito pode ser remático, dicente ou argumentativo. Mas, ele também pode predominar, na relação com seu objeto, como índice e, nesse caso, o efeito pode ser remático ou dicente.

Figura 2: Diagrama para dez classes de signos

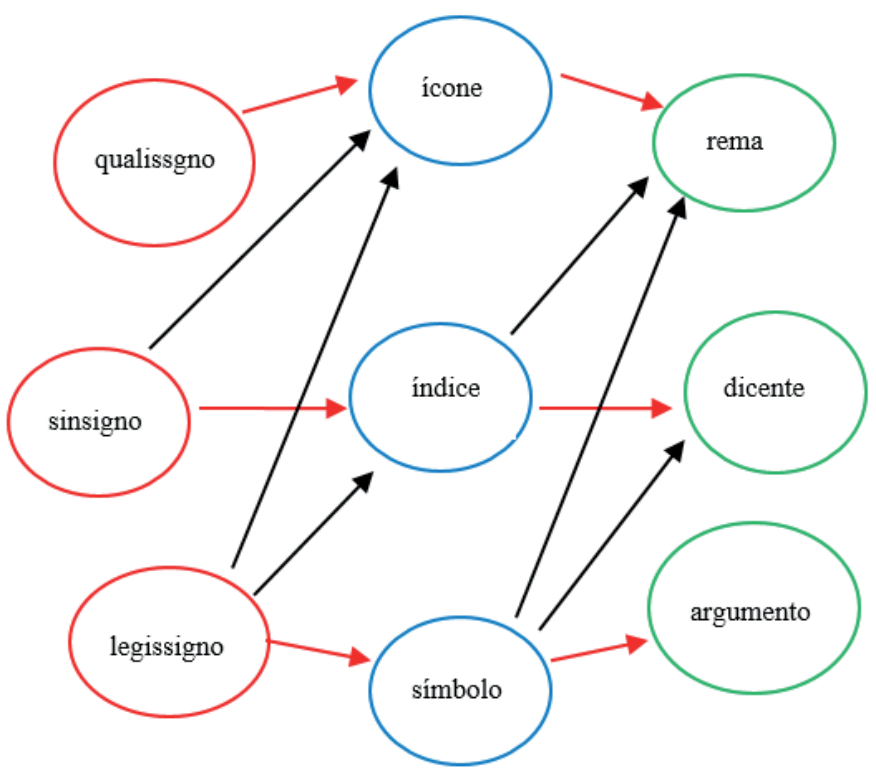

Fonte: DRIG0; SOUZA (2013, p. 64) 
Há estudos mais minuciosos que explicitam 66 classes - Peirce só alertou os seus leitores para essa possibilidade -, mas não as explicitou. As dez classes constam em uma carta à Lady Welby, de 1904. (PEIRCE, 1998, p. 167-177)

Essa mobilidade, visualizada no diagrama (Fig. 2), incita 0 intérprete a considerar que, nos processos interpretativos, a ação do signo pode se prolongar e propiciar efeitos diferenciados. Não há um mundo de signos separado do mundo das coisas, com instâncias estanques.

Mas 0 que é mais relevante para 0 âmbito deste artigo são as mínimas diferenças no movimento da percepção à cognição que, de certo modo, contribuem para a compreensão do movimento do pensamento com "imagens", em um primeiro momento na seara da segundidade e, em seguida, permanecendo nesta ou adentrando a terceiridade.

\section{Considerações finais}

No contexto das imagens cinematográficas, a imagem-movimento, nas suas três divisões, prevalece na segundidade. No entanto, considerando-se a possibilidade de que a consciência sintética se instaure, vislumbra-se a possibilidade da imagem-cinematográfica, enquanto signo na perspectiva peirciana, predominar como sinsigno - como réplica de legissigno - e, assim, desencadear a semiose, ou ação do signo genuíno... adentrando a seara da terceiridade.
Retomemos as contribuições que vêm desta reflexão. Em primeiro lugar, deste primeiro olhar para os conceitos de Deleuze vinculados aos peircianos, inferimos que não seria pertinente a classificação dada à imagem-percepção. Esta seria adequada à imagem-ação, enquanto efeito possível da imagem-percepção. Em segundo lugar, constatamos a importância de ter as categorias como guia para a elaboração de estratégias metodológicas para análise de imagem em movimento.

Vejamos como isso é possível. Nas palavras de Deleuze (2009, p. 113):

Nunca um filme é feito de um único tipo de imagens: chama-se precisamente montagem à combinação das três variedades. A montagem (num dos seus aspectos) é 0 agenciamento das imagens-movimento e portanto 0 interagenciamento das imagens-percepção, das imagens-afecção e das imagens-ação. (...) Aos três tipos de variedades pode-se fazer corresponder três tipos de planos espacialmente determinados: 0 plano de conjunto será sobretudo uma imagem-percepção, o plano médio uma imagem-ação e o grande plano uma imagem-afecção.

Porém, considerando-se que Deleuze (2009, p. 113-

4), seguindo uma indicação de Eisenstein, explica que "cada uma destas imagens-movimento é um ponto de vista sobre o todo do filme, uma maneira de captar esse todo, que se torna afetivo, no grande plano, ativo no plano médio e perceptivo no plano de conjunto, deixando cada um destes planos de ser espacial para se tornar em si mesmo uma 'leitura' de todo o filme", o que nos leva a constatar a importância das categorias fenomenológicas na análise da imagem-movimento. 
Assim, com um inventário de planos e de suas especificidades, pode-se elencar os seus possíveis efeitos, o que corresponde a avaliar o nível de consciência que prepondera no intérprete e, em última instância, a categoria fenomenológica que pode reinar. Esta classificação, que vamos tratar ainda no desenvolvimento da pesquisa mencionada na introdução, foi desenvolvida por Deleuze e contribuiu, em certa medida, para traçar aspectos históricos do cinema, embora esta não fosse a sua pretensão, conforme deixou claro no início da obra A imagem-movimento Cinema I.

\section{Referências}

DELEUZE, Gilles. A imagem-movimento. Cinema 1. Lisboa: Assírio \& Alvim, 2009.

DRIGO, Maria Ogécia. Comunicação e cognição: semiose na mente humana. Porto Alegre: Sulina, 2007. DRIG0, Maria Ogécia; SOUZA, Luciana. C. P. de. Aulas de semiótica peirceana. São Paulo: Annablume, 2013. HARTSHORNE, C.; WEISS, P. 1994 [1959]. The collected papers of Charles Sanders Peirce. Cambridge, Harvard University Press. [CD-ROM]. MOSTAFA, Solange Puntel; CRUZ, Denise Viuniski da Nova. Deleuze vai ao cinema. São Paulo: Alínea, 2011.

PARENTE, André. Cinema/Deleuze. Campinas: Papirus, 2013.

PEIRCE, Charles Sanders. Antologia Filosófica.

Portugal/Imprensa Nacional: Casa da Moeda, 1998.

SANTAELLA, Lucia. A percepção: uma teoria semiótica. São Paulo: Experimento, 1998.

SILVA, Alexandre da R.; Araújo, André C. da S. Semioses do movimento e do tempo no cinema

1. Intercom - Sociedade Brasileira de Estudos
Interdisciplinares da Comunicação XXXIV Congresso Brasileiro de Ciências da Comunicação - Recife, PE - 2 a 6 de setembro de 2011. Disponível em: < http://www. intercom.org.br/papers/nacionais/2011/resumos/R61357-1.pdf> . Acesso em: 10 jan. 2015. 


\section{Cinematic image and thought: the perception image at the confluence of Deleuze's and Peirce's theories}

\section{Abstract}

This paper presents results of a research whose theme is the relations between thought and cinematic images developed by Gilles Deleuze, in the book Movement Image Cinema 1, at the confluence with Charles Sanders Peirce's theories, especially the taxonomy of signs and phenomenological categories. In order to achieve its goal, which is to explain the approaches between perception-image, which is a component of the movement-image, concept proposed by Deleuze in the referred book, to the theory of perception and phenomenological categories in Peirce's perspective, as well as review the classification given by Deleuze to the image-perception, according to Peirce's classification, one presents reflections on the concept of movement-image, about the theory of perception and phenomenology of philosophical architecture undertaken by Peirce and, finally, one explores the classification of the perception image elaborated by Deleuze. The importance of this paper lies upon evidencing the potentiality to interlace Deleuze's and Peirce's ideas in the analysis of movement images.

\section{Keywords}

Deleuze/Peirce. Cinematic image. Perception image.

\section{Imagen cinematográfica y} pensamiento: la imagen-percepción

\section{en la confluencia de las teorías de} Deleuze y Peirce

\section{Resumen}

Este artículo presenta los resultados de investigación que envuelven las relaciones entre el pensamiento y las imágenes cinematográficas desarrolladas por Gilles Deleuze, en la obra La Imagen-movimiento: Cine 1, en la confluencia con las teorías de Charles Sanders Peirce, especialmente la taxonomía de los signos y categorías fenomenológicas. Con el fin de lograr el objetivo de explicitar las similitudes entre la imagen-percepción, la componente de imagenmovimiento, concepto propuesto por Deleuze en esta obra, a la teoría de la percepción y categorías fenomenológicas en perspectiva de Peirce, así como la revisión de la clasificación dada por Deleuze la imagen -percepção, según la clasificación de Peirce, se presentan reflexiones sobre el concepto de imagen-movimiento, sobre la teoría de la percepción y de la fenomenología de la arquitectura filosófica llevada a cabo por Peirce y finalmente exploramos la clasificación de la imagen-percepción elaborada por Deleuze. La importancia de este artículo es poner de relieve la interrelación potencial de ideas y Peirce de Deleuze para el análisis de imágenes en movimiento.

\section{Palabras clave}

Deleuze/Peirce. Imagen cinematográfica.

Imagen-percepción. 


\section{Expediente}

A revista E-Compós é a publicação científica em formato eletrônico da Associação Nacional dos Programas de Pós-Graduação em Comunicação (Compós). Lançada em 2004, tem como principal finalidade difundir a produção acadêmica de pesquisadores da área de Comunicação, inseridos em instituições do Brasil e do exterior.

\section{E-COMPÓS I www.e-compos.org.br I E-ISSN 1808-2599}

Revista da Associação Nacional dos Programas de Pós-Graduação em Comunicação. Brasília, v.19, n.2, maio/ago. 2016. A identificação das edições, a partir de 2008, passa a ser volume anual com três números. Indexada por Latindex I www.latindex.unam.mx

\section{CONSELHO EDITORIAL}

\section{Alexandre Farbiarz, Universidade Federal Fluminense, Brasi}

Alexandre Rocha da Silva, Universidade Federal do Rio Grande do Sul, Brasil Ana Carolina Escosteguy, Pontifícia Universidade Católica do Rio Grande do Sul, Brasil Ana Carolina Rocha Pessôa Temer, Universidade Federal de Goiás, Brasil Ana Regina Barros Rego Leal, Universidade Federal do Piauí, Brasil Andrea França, Pontifícia Universidade Católica do Rio de Janeiro, Brasil André Luiz Martins Lemos, Universidade Federal da Bahia, Brasil Antonio Carlos Hohlfeldt, Pontifícia Universidade Católica do Rio Grande do Sul, Brasil Arthur Ituassu, Pontifícia Universidade Católica do Rio de Janeiro, Brasil Álvaro Larangeira, Universidade Tuiuti do Paraná, Brasil

Ângela Freire Prysthon, Universidade Federal de Pernambuco, Brasil César Geraldo Guimarães, Universidade Federal de Minas Gerais, Brasil Cláudio Novaes Pinto Coelho, Faculdade Cásper Líbero, Brasil Daisi Irmgard Vogel, Universidade Federal de Santa Catarina, Brasil Denize Correa Araujo, Universidade Tuiuti do Paraná, Brasil Eduardo Antonio de Jesus, Pontifícia Universidade Católica de Minas Gerais, Brasil Daniela Zanetti, Universidade Federal do Espírito Santo, Brasil Eduardo Vicente, Universidade de São Paulo, Brasil

Elizabeth Moraes Gonçalves, Universidade Metodista de São Paulo, Brasil Erick Felinto de Oliveira, Universidade do Estado do Rio de Janeiro, Brasil Francisco Elinaldo Teixeira, Universidade Estadual de Campinas, Brasil Francisco Paulo Jamil Almeida Marques, Universidade Federal do Paraná, Brasil Gabriela Reinaldo, Universidade Federal do Ceará, Brasil

Goiamérico Felício Carneiro Santos, Universidade Federal de Goiás, Brasil Gustavo Daudt Fischer, Universidade do Vale do Rio dos Sinos, Brasil Herom Vargas, Universidade Municipal de São Caetano do Sul, Brasil Itania Maria Mota Gomes, Universidade Federal da Bahia, Brasil Janice Caiafa, Universidade Federal do Rio de Janeiro, Brasil Jiani Adriana Bonin, Universidade do Vale do Rio dos Sinos, Brasil
José Afonso da Silva Junior, Universidade Federal de Pernambuco, Brasil José Luiz Aidar Prado, Pontifícia Universidade Católica de São Paulo, Brasil Juçara Gorski Brittes, Universidade Federal de Ouro Preto, Brasil Kati Caetano, Universidade Tuiuti do Paraná, Brasil Lilian Cristina Monteiro França, Universidade Federal de Sergipe, Brasil Liziane Soares Guazina, Universidade de Brasilia, Brasil Luíza Mônica Assis da Silva, Universidade de Caxias do Sul, Brasil Luciana Miranda Costa, Universidade Federal do Pará, Brasil Malena Segura Contrera, Universidade Paulista, Brasil Monica Martinez, Universidade de Sorocaba, Brasil Maria Ataide Malcher, Universidade Federal do Pará, Brasil Marcia Tondato, Escola Superior de Propaganda e Marketing, Brasil Marcel Vieira Barreto Silva, Universidade Federal da Paraiba, Brasil Maria Clotilde Perez Rodrigues, Universidade de São Paulo, Brasil Maria das Graças Pinto Coelho, Universidade Federal do Rio Grande do Norte, Brasil Mauricio Ribeiro da Silva, Universidade Paulista, Brasil

Mauro de Souza Ventura, Universidade Estadual Paulista, Brasil Márcio Souza Gonçalves, Universidade do Estado do Rio de Janeiro, Brasil Micael Maiolino Herschmann, Universidade Federal do Rio de Janeiro, Brasil Mirna Feitoza Pereira, Universidade Federal do Amazonas, Brasil Nísia Martins Rosario, Universidade Federal do Rio Grande do Sul, Brasil Potiguara Mendes Silveira Jr, Universidade Federal de Juiz de Fora, Brasil Regiane Regina Ribeiro, Universidade Federal do Paraná, Brasil Rogério Ferraraz, Universidade Anhembi Morumbi, Brasil Rose Melo Rocha, Escola Superior de Propaganda e Marketing, Brasil Rozinaldo Antonio Miani, Universidade Estadual de Londrina, Brasil Sérgio Luiz Gadini, Universidade Estadual de Ponta Grossa, Brasil Simone Maria Andrade Pereira de Sá, Universidade Federal Fluminense, Brasil Veneza Mayora Ronsini, Universidade Federal de Santa Maria, Brasil Walmir Albuquerque Barbosa, Universidade Federal do Amazonas, Brasil
COMISSÃO EDITORIAL Eduardo Antonio de Jesus, Pontifícia Universidade Católica de Minas Gerais, Brasil I Osmar Gonçalves dos Reis Filho, Universidade Federal do Ceará, Brasi

CONSULTORES AD HOC Alexandre Almeida Barbalho, Universidade Estadual do Ceará, Brasil | Alexandre Rocha da Silva, Universidade Federal do Rio Grande do Sul, Brasil | Bruno Souza Leal, Universidade Federal de Minas Gerais, Brasil I Carlos Eduardo Franciscato, Universidade Federal do Sergipe, Brasil I Eneus T. Barreto Filho, Universidade de São Paulo, Brasil I Felipe da Costa Trotta, Universidade Federal Fluminense, Brasi | Henrique Codato, Universidade Federal do Ceará, Brasil I Ines S. Vitorino Sampaio Universidade Federal do Ceará, Brasil I Jairo Getulio Ferreira, Universidade do Vale do Rio dos Sinos, Brasil I Juliana Freire Gutmann, Universidade Federal da Bahia, Brasil | Júlio César M. Pinto, Pontifícia Universidade Católica de Minas Gerais, Brasil I Lucrecia D. Ferrara, Pontifícia Universidade Católica de São Paulo, Brasil I Marcio V. Serelle, Pontifícia Universidade Católica de Minas Gerais, Brasil I Maria Ignes C. Magno, Universidade Anhemb Morumbi, Brasil I Maria Lilia Dias de Castro, Universidade Federal de Santa Maria, Brasil | Mozahir S. Bruck, Pontifícia Universidade Católica de Minas Gerais, Brasil I Potiguara M. da Silveira Junior, Universidade Federal de Juiz de Fora, Brasil I Sandra Maria L. P. Gonçalves, Universidade Federal do Rio Grande do Sul, Brasil I Suzana Kilpp, Universidade do Vale do Rio dos Sinos, Brasil I Tiago Q. Fausto Neto, Universidade de Brasília, Brasil I Vera Regina V. Franca, Universidade Federal de Minas Gerais, Brasil I Virginia P. S. Fonseca, Universidade Federal do Rio Grande do Sul, Brasil

EQUIPE TÉCNICA ASSISTENTE EDITORIAL Márcio Zanetti Negrini REVISÃo DE TEXTOS Press Revisão I EDITORAÇÃO ELETRÔNICA Roka Estúdio

\section{COMPÓS I www.compos.org.br}

Associação Nacional dos Programas de Pós-Graduação em Comunicação

Presidente

Edson Fernando Dalmonte

Programa de Pós-Graduação em Comunicação

e Cultura Contemporânea - UFBA

edsondalmonte@uol.com.br

Vice-presidente

Cristiane Freitas Gutfreind

Programa de Pós-Graduação em Comunicação Social - PUC-RS cristianefreitas@pucrs.br

Secretário-Geral

Rogério Ferraraz

Programa de Pós-Graduação em Comunicação

Universidade Anhembi Morumbi

rogerioferraraz@anhembimorumbi.edu.br

CONTATO I revistaecompos@gmail.com 